\title{
Silicon Carbide Grains of Type X and Supernova Nucleosynthesis
}

\author{
Ernst Zinner ${ }^{1}$ \\ Laboratory for Space Sciences and Physics Department, Washington University \\ St. Louis, MO 63130, USA \\ E-mail: ekz@wustl.edu
}

Frank Gyngard

Department of Terrestrial Magnetism, Carnegie Institution of Washington

Washington, DC 20015, USA

E-mail: fgyngardedtm.ciw.edu

\section{Yangting Lin}

Key Laboratory of the Earth's Deep Interior, Institute of Geology and Geophysics, Chinese Academy of

Sciences

Beijing 100029, China

E-mail: linyt@mail.igcas.ac.cn

Silicon carbide grains of type $\mathrm{X}$ constitute $\sim 1 \%$ of all presolar SiC grains found in primitive meteorites. These grains have ${ }^{15} \mathrm{~N}$ and ${ }^{28} \mathrm{Si}$ excesses, mostly light $\mathrm{C}$, high inferred ${ }^{26} \mathrm{Al} /{ }^{27} \mathrm{Al}$ ratios, and evidence (from ${ }^{44} \mathrm{Ca}$ and ${ }^{49} \mathrm{Ti}$ excesses) for the initial presence of the short-lived radioisotopes ${ }^{44} \mathrm{Ti}$ and ${ }^{49} \mathrm{~V}$. These isotopic signatures clearly indicate an origin in the ejecta of Type II supernovae ( $\mathrm{SNe}$ ) and material from different SN zones had to contribute to the mix from which the grains formed: $\mathrm{He} / \mathrm{N}\left({ }^{26} \mathrm{Al}\right), \mathrm{He} / \mathrm{C}\left({ }^{12} \mathrm{C}\right.$ and $\left.{ }^{15} \mathrm{~N}\right)$, and the $\mathrm{Si} / \mathrm{S}$ zone $\left({ }^{28} \mathrm{Si},{ }^{44} \mathrm{Ti},{ }^{49} \mathrm{~V}\right)$. However, in detail there are many discrepancies between grain data and theoretical predictions from SN models. One major discrepancy concerns the distribution of the $\mathrm{Si}$ isotopic ratios. In a Si 3-isotope plot, most grains plot along a line, which points to a primary isotopic composition with ${ }^{29} \mathrm{Si} /{ }^{28} \mathrm{Si} \approx 1 / 3 \times$ solar and almost no ${ }^{30} \mathrm{Si}$. However, such a composition is not produced by any of the $\mathrm{SN}$ models. Another set of discrepancies involves the correlation between $\mathrm{C}, \mathrm{N}$ and $\mathrm{Al}$ isotopic ratios: ${ }^{12} \mathrm{C} /{ }^{13} \mathrm{C}$ and ${ }^{15} \mathrm{~N} /{ }^{14} \mathrm{~N}$ ratios are high in the $\mathrm{He} / \mathrm{C}$ and low in the $\mathrm{He} / \mathrm{N}$ zone, whereas the ${ }^{26} \mathrm{Al} /{ }^{27} \mathrm{Al}$ ratios show the opposite behavior. As a consequence, mixing between these zones results in negative correlations between these ratios, in contrast to the grain data. Another example is the lack of large ${ }^{54} \mathrm{Fe}$ excesses in $\mathrm{X}$ grains. While mixing with material from the $\mathrm{Si} / \mathrm{S}$ zone, rich in ${ }^{28} \mathrm{Si}$, is necessary to explain the ${ }^{28} \mathrm{Si}$ excesses in these grains, the ${ }^{54} \mathrm{Fe}$, also abundant in this zone, must have been separated from the ${ }^{28} \mathrm{Si}$ before grain condensation by a process still not understood.

11th Symposium on Nuclei in the Cosmos - NIC XI

Heidelberg, Germany

July 19-23 2010

1 Speaker 


\section{Introduction}

Silicon carbide grains of type $\mathrm{X}$ make up $\sim 1 \%$ of all presolar $\mathrm{SiC}$ grains found in primitive meteorites [1]. These grains have high ${ }^{12} \mathrm{C} /{ }^{13} \mathrm{C}$ and low ${ }^{14} \mathrm{~N} /{ }^{15} \mathrm{~N}$ ratios (Fig. 1). They also have large ${ }^{28} \mathrm{Si}$ excesses (Fig. 2) and high inferred (from large ${ }^{26} \mathrm{Mg}$ excesses) ${ }^{26} \mathrm{Al} /{ }^{27} \mathrm{Al}$ ratios. These isotopic signatures indicate an origin in Type II SNe. Absolute proof for a SN origin comes from evidence for the initial presence of ${ }^{44} \mathrm{Ti}\left(\mathrm{T}_{1 / 2}=60 \mathrm{yrs}\right)$ in the form of ${ }^{44} \mathrm{Ca}$ excesses. ${ }^{44} \mathrm{Ti}$ is only produced in $\mathrm{SNe}[2]$.

Although the isotopic compositions of the grains leave no doubt that they came from $\mathrm{SNe}$, in detail there are many discrepancies between isotopic data and theoretical predictions from SN models [3].

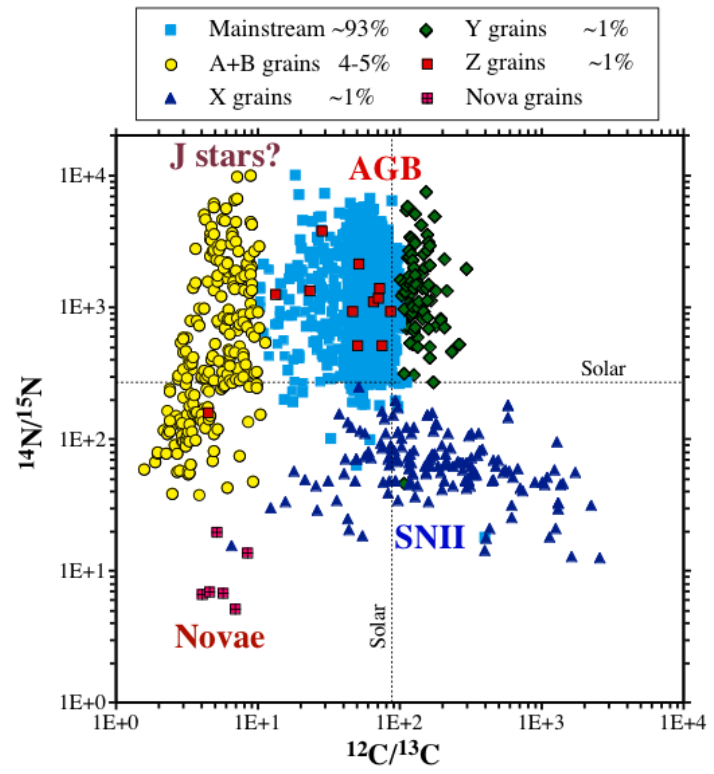

Figure 1. Nitrogen and carbon isotopic ratios of individual presolar $\mathrm{SiC}$ grains. The grains can be grouped based on their $\mathrm{C}, \mathrm{N}$, $\mathrm{Al}$, and $\mathrm{Si}$ isotopic ratios. The isotopic ratios of $\mathrm{X}$ grains indicate a $\mathrm{SN}$ origin. All isotopic ratios of $\mathrm{SiC}$ grains shown in this and subsequent plots are taken from the presolar data base [4].

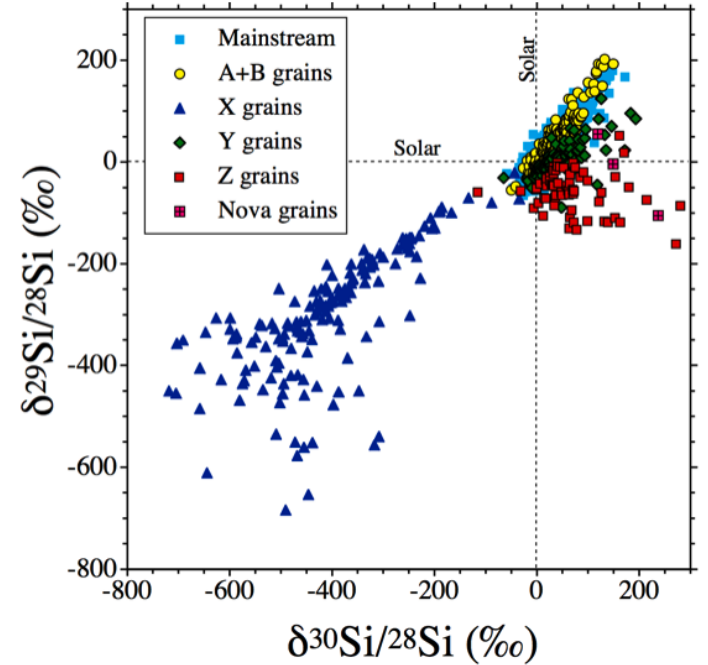

Figure 2. Silicon isotopic ratios of individual presolar $\mathrm{SiC}$ grains. The ratios are expressed in $\delta$-values, deviations from the solar ratios in parts per thousand (\%o). X grains show ${ }^{28} \mathrm{Si}$ excesses.

\section{Isotopic ratios and comparison with $\mathrm{SN}$ models}

We compare selected isotopic ratios in X grains with SN predictions. Fig. 3 shows isotopic ratios (normalized to solar ratios) and isotopic abundances in the interior layers of the $25 \mathrm{M}_{\odot}$ SN model s25a28d (http://nucastro.org/nucleosynthesis/) by Rauscher et al. [5]. The He/N and $\mathrm{He} / \mathrm{C}$ zones are the only regions with $\mathrm{C}>\mathrm{O} .{ }^{28} \mathrm{Si},{ }^{44} \mathrm{Ti}$, and ${ }^{49} \mathrm{~V}$ are produced in the inner $\mathrm{Si} / \mathrm{S}$ and $\mathrm{O} / \mathrm{Si}$ zones. The isotopic ratios of $\mathrm{X}$ grains and the condition of $\mathrm{C}>\mathrm{O}$ for $\mathrm{SiC}$ condensation require mixing of material from different $\mathrm{SN}$ layers. 


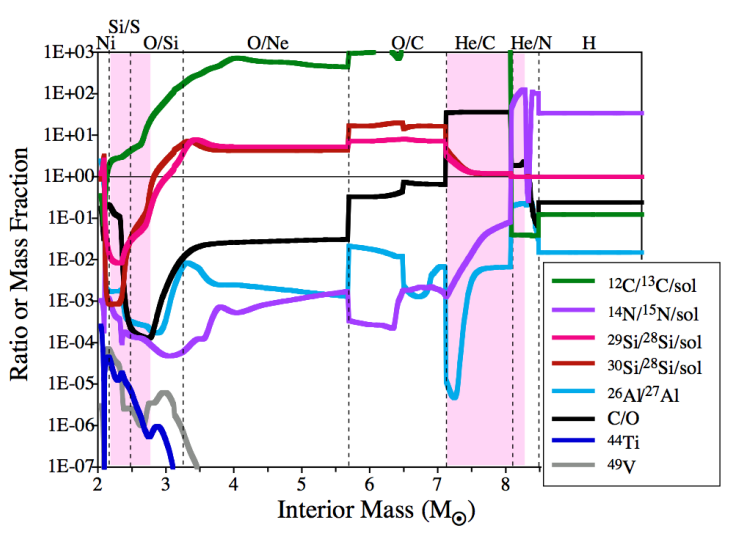

Figure 3. Theoretical predictions of the isotopic abundances and ratios in the interior of a $25 \mathrm{M}_{\odot}$ supernova from the model by Rauscher et al. [5]. For stable isotopes the isotopic ratios are normalized to the solar ratios; for the short-lived radioisotopes ${ }^{44} \mathrm{Ti}$ and ${ }^{49} \mathrm{~V}$ the mass fractions are given. Also given is the $\mathrm{C} / \mathrm{O}$ ratio. $\mathrm{C} / \mathrm{O}>1$ is believed to be a necessary condition for the condensation of $\mathrm{SiC}$. The isotopic signatures of $\mathrm{X}$ grains indicate mixing between the zones with pink color.

\subsection{Carbon, nitrogen and aluminum isotopic ratios}

Mixing between the $\mathrm{He} / \mathrm{N}$ and $\mathrm{He} / \mathrm{C}$ zone (Fig. 4) can reproduce the $\mathrm{C}$ and $\mathrm{N}$ isotopic ratios of most $\mathrm{X}$ grains but only if one takes material from the layer with the ${ }^{15} \mathrm{~N}$ spike (sharp crevice in the ${ }^{14} \mathrm{~N} /{ }^{15} \mathrm{~N}$ ratio at $8.33 \mathrm{M} \odot$ ) in the $\mathrm{He} / \mathrm{N}$ zone (Fig. 3). Even then, there are grains that plot below the lowest mixing line. In addition, not all SN models (other masses or [6]) have the ${ }^{15} \mathrm{~N}$ spike. This is an issue that needs exploration.

The situation is worse for the $\mathrm{Al}$ isotopic ratios. Mixing between the $\mathrm{He} / \mathrm{N}$ (high ${ }^{26} \mathrm{Al} /{ }^{27} \mathrm{Al}$ and low ${ }^{12} \mathrm{C} /{ }^{13} \mathrm{C}$ ) and $\mathrm{He} / \mathrm{C}$ zone (low ${ }^{26} \mathrm{Al} /{ }^{27} \mathrm{Al}$ and high ${ }^{12} \mathrm{C} /{ }^{13} \mathrm{C}$; Fig. 5) produces an anticorrelation between the ${ }^{26} \mathrm{Al} /{ }^{27} \mathrm{Al}$ and ${ }^{12} \mathrm{C} /{ }^{13} \mathrm{C}$ ratios (same mixing curves as in Fig. 4). However, the grain data do not show this (Fig. 5). In addition, some grains have higher ${ }^{26} \mathrm{Al} /{ }^{27} \mathrm{Al}$ ratios than those produced in any of the layers of the SN models.

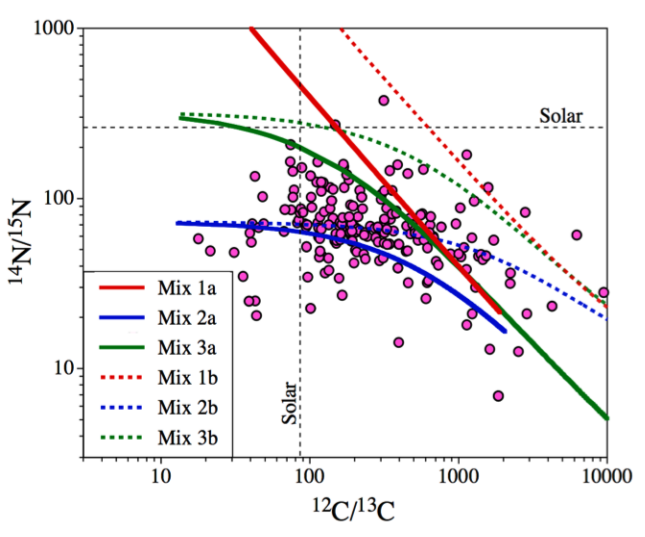

Figure 4. Nitrogen isotopic ratios of $\mathrm{X}$ grains plotted against the $\mathrm{C}$ isotopic ratios. The lines are predicted isotopic ratios obtained by mixing layers from the $\mathrm{He} / \mathrm{C}$ zone (a: at $7.24 \mathrm{M}_{\odot}$, b: at $7.6 \mathrm{M}_{\odot}$ interior mass) with layers of the $\mathrm{He} / \mathrm{N}$ zone (1: at $8.2 \mathrm{M}_{\odot}, 2$ : at $8.33 \mathrm{M}_{\odot}\left({ }^{15} \mathrm{~N}\right.$ spike $), 3: 20 \%$ of the $\mathrm{He} / \mathrm{N}$ zone centered at the ${ }^{15} \mathrm{~N}$ spike at $\left.8.33 \mathrm{M}_{\odot}\right)$ of the $25 \mathrm{M}_{\odot}$ supernova model by Rauscher et al. [5].

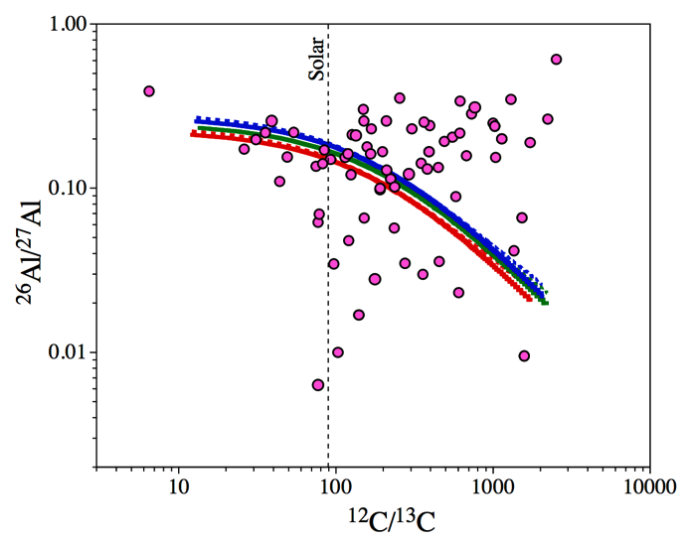

Figure 5. Inferred $\mathrm{Al}$ isotopic ratios of $\mathrm{X}$ grains plotted against the $\mathrm{C}$ isotopic ratios. The lines are predicted isotopic ratios obtained by mixing layers as in Fig. 4 .

\subsection{Silicon isotopic ratios}

Mixing between at least three different zones (e.g., $\mathrm{Si} / \mathrm{S}, \mathrm{O} / \mathrm{Ne}$ and $\mathrm{He} / \mathrm{C}$ ) is required to explain the $\mathrm{Si}$ isotopic compositions of $\mathrm{X}$ grains (Fig. 6). However, this requires completely ad hoc assumptions and does not explain the trend shown by most $X$ grains. A primary component close to the star symbol is required to account for this trend. 


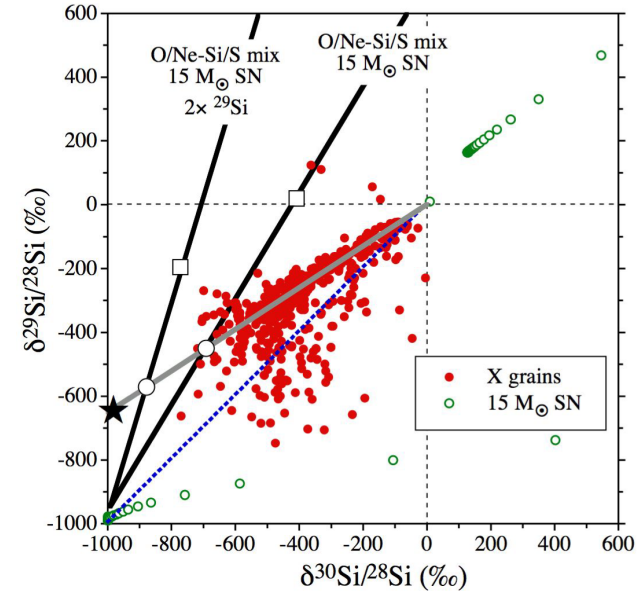

Figure 6. Silicon isotopic ratios of $\mathrm{X}$ grains are compared to ratios predicted by the 15 $\mathrm{M}_{\odot}$ supernova model by Rauscher et al. [5]. The gray line is the correlation line for most $\mathrm{X}$ grains. The broken blue line represents a mix between the $\mathrm{Si} / \mathrm{S}$ zone and the $\mathrm{He} / \mathrm{N}$ and $\mathrm{He} / \mathrm{C}$ zones. Points on the gray correlation line can be reached by mixing contributions from the $\mathrm{O} / \mathrm{Ne}$ zone with the $\mathrm{Si} / \mathrm{S}$ zone. The black star represents a putative primary composition that would best explain the gray correlation line.

\subsection{Titanium and iron isotopic ratios}

In the $\mathrm{Si} / \mathrm{S}$ zone there are high abundances of ${ }^{46} \mathrm{Ti}$ and ${ }^{54} \mathrm{Fe}$ (Fig. 7). Since ${ }^{28} \mathrm{Si}$ from this zone is needed to explain the ${ }^{28} \mathrm{Si}$ excesses in X grains (Fig. 3), one expects to find large ${ }^{46} \mathrm{Ti}$ and ${ }^{54} \mathrm{Fe}$ excesses. However, the grain data do not show such excessses [3,

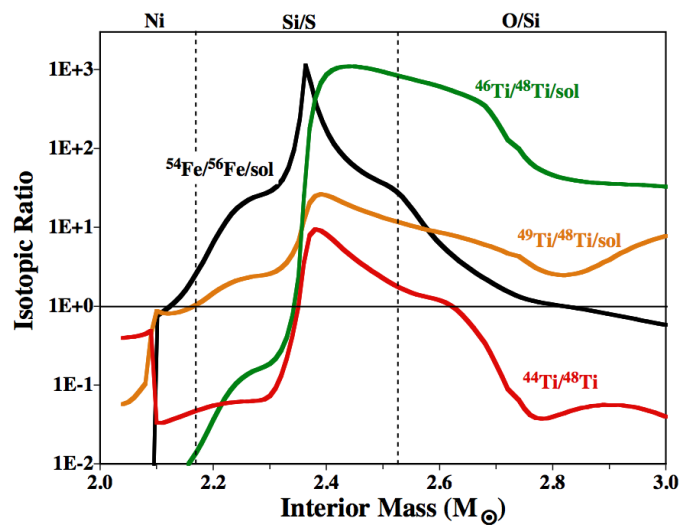

Figure 7. Titanium and $\mathrm{Fe}$ isotopic ratios in the inner $\mathrm{SN}$ zones predicted from the $25 \mathrm{M}_{\odot}$ supernova model by Rauscher et al. [5]. Ratios of stable isotopes (for ${ }^{49} \mathrm{Ti}$ after decay of ${ }^{49} \mathrm{~V}$ ) are normalized to solar ratios.
7]. The lines in Fig. 8 show compositions expected for mixtures of $\mathrm{He} / \mathrm{N}-\mathrm{He} / \mathrm{C}$ material, which has a $\delta^{46} \mathrm{Ti}{ }^{48} \mathrm{Ti}$ value close to $0 \%$, with material from different layers in the $\mathrm{Si} / \mathrm{S}$ and $\mathrm{O} / \mathrm{Si}$ zones. If only material from the inner $\mathrm{Si} / \mathrm{S}$ zone contributes, then large ${ }^{46} \mathrm{Ti}$ excesses can be avoided. However, even then large ${ }^{54} \mathrm{Fe}$ excesses are expected, which are not observed (Fig. 9).

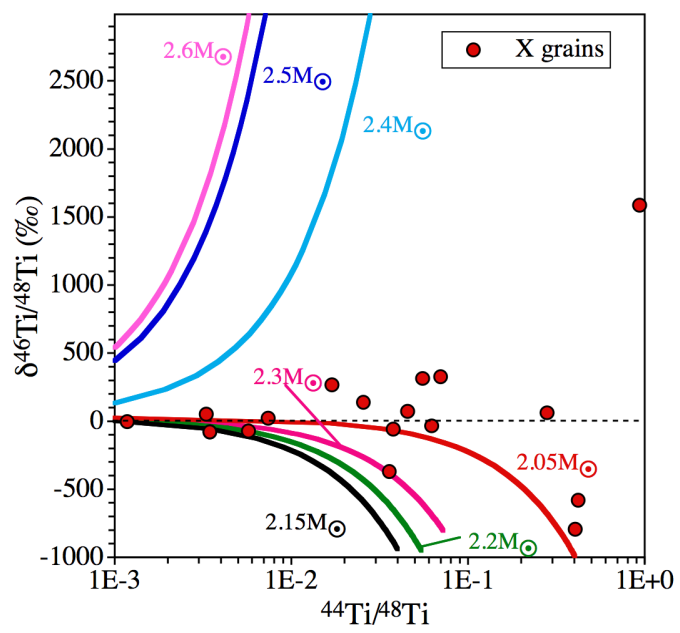

Figure 8. Titanium isotopic ratios of $\mathrm{X}$ grains and compositions expected for mixtures of $\mathrm{He} / \mathrm{N}-\mathrm{He} / \mathrm{C}$ material with material from different layers (interior mass labels in the plot) in the $\mathrm{Si} / \mathrm{S}$ and $\mathrm{O} / \mathrm{Si}$ zones of the $25 \mathrm{M}_{\odot}$ supernova model by Rauscher et al. [5].

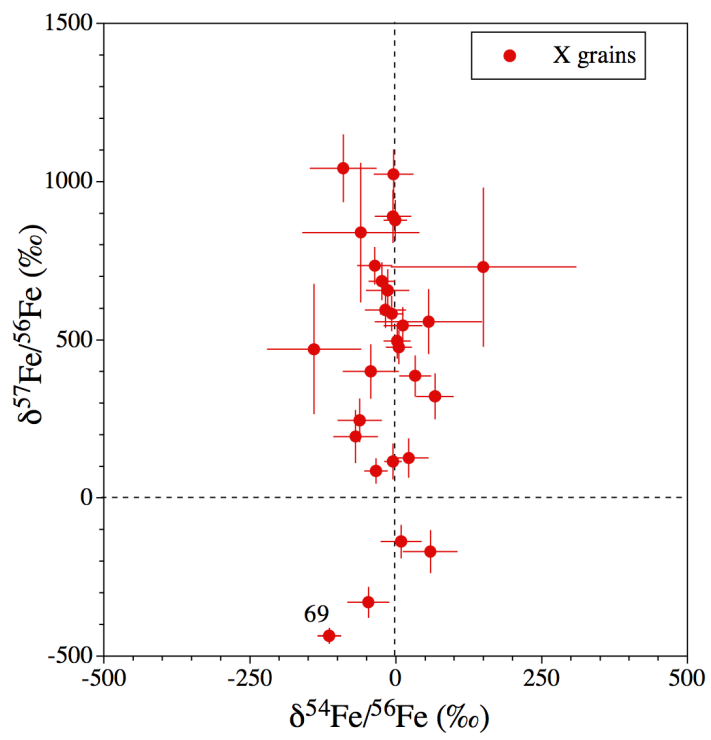

Figure 9. Iron isotopic ratios of $\mathrm{X}$ grains [7]. 


\section{Conclusions}

We have shown that in several cases SN models do not produce isotopic ratios measured in SN grains in great detail, especially correlations between isotopic systems. At present, it is not clear where improvements could be found. We have to explore a larger range of stellar masses and look at models including stellar rotations. However, it is clear that one-dimensional models of SN nucleosynthesis are far too simplistic. Mixing is one of the poorly understood processes that play an important role in SN nucleosynthesis. Two- and three-dimensional models show that mixing between different SN zones is extremely complex, with material from inner layers ploughing into or overtaking outer layers $[8,9]$. Following multi-dimensional mixing with nuclear reaction networks exceeds present computer capabilities and we have to await progress. Another question is how the condensation behaviour of various species affects what elements of a given zone end up in a SN grain [10]. For example, Fe from the $\mathrm{Si} / \mathrm{S}$ zone might condense into $\mathrm{FeS}$ grains and could be separated from the $\mathrm{Si}$, so that $\mathrm{Fe}$ from this zone was not included in the $\mathrm{X}$ grains, whereas Si was. Presently, this is pure conjecture. However, it might be possible to perform condensation calculations while following multi-dimensional mixing [11] and obtain information about possible fractionation between different elements. Thus, while we are still far away from an understanding of the discrepancies between grain data and SN model, we can see several paths to be taken that might lead to progress.

\section{Acknowledgments}

The comments of an anonymous reviewer improved the manuscript. This work was supported by NASA grant NNX08AG71G.

\section{References}

[1] E. Zinner, Presolar grains, in: Treatise on Geochemistry Update, H. D. Holland, K. K. Turekian and A. Davis, eds., pp. 1, Elsevier Ltd., Oxford, 2007.

[2] F. X. Timmes, S. E. Woosley, D. H. Hartmann and R. D. Hoffman, The production of ${ }^{44}$ Ti and ${ }^{60}$ Co in supernovae, Astrophys. J. 464, 332, 1996.

[3] Y. Lin, F. Gyngard and E. Zinner, Isotopic analysis of supernova SiC and $\mathrm{Si}_{3} \mathrm{~N}_{4}$ grains from the Qingzhen (EH3) chondrite, Astrophys. J. 709, 1157, 2010.

[4] K. M. Hynes and F. Gyngard, The presolar grain database: http://presolar.wustl.edu/ pgd., Lunar Planet. Sci. XL, Abstract \#1198, 2009.

[5] T. Rauscher, A. Heger, R. D. Hoffman and S. E. Woosley, Nucleosynthesis in massive stars with improved nuclear and stellar physics, Astrophys. J. 576, 323, 2002.

[6] M. Limongi and A. Chieffi, The nucleosynthesis of ${ }^{26} \mathrm{Al}$ and ${ }^{60} \mathrm{Fe}$ in solar metallicity stars extending in mass from 11 to $120 \mathrm{M \odot :} \mathrm{The} \mathrm{hydrostatic} \mathrm{and} \mathrm{explosive} \mathrm{contributions,} \mathrm{Astrophys.} \mathrm{J.} \mathrm{647,} \mathrm{483,}$ 2006.

[7] K. K. Marhas, S. Amari, F. Gyngard, E. Zinner and R. Gallino, Iron and nickel isotopic ratios in presolar SiC grains, Astrophys. J. 689, 622, 2008.

[8] K. Kifonidis, T. Plewa, H.-Th. Janka and E. Müller, Non-spherical core collapse supernovae I. Neutrino-driven convection, Rayleigh-Taylor instabilities, and the formation and propagation of metal clumps, Astron. Astrophys. 408, 621, 2003.

[9] N. J. Hammer, H.-Th. Janka and E. Müller, Three-dimensional simulations of mixing instabilities in supernova explosions, Astrophys. J. 714, 1371, 2010.

[10] Hoppe P., Leitner J., Gröner E., Marhas K. K., Meyer B. S., and Amari S. (2010) NanoSIMS studies of small presolar SiC grains: New insights into supernova nucleosynthesis, chemistry, and dust formation. Astrophys. J. 719, 1370-1384.

[11] A. V. Fedkin, B. S. Meyer and L. Grossman, Condensation and mixing in supernova ejecta, Geochim. Cosmochim. Acta 74, 3642, 2010. 